\title{
Immunophenotypical Characterization of M1/M2 Macrophages and Lymphocytes in Cisplatin-Induced Rat Progressive Renal Fibrosis
}

\author{
Minto Nakagawa ${ }^{1}$, Mohammad Rabiul Karim ${ }^{1,2}{ }^{10}$, Takeshi Izawa ${ }^{1}{ }^{\oplus}$, Mitsuru Kuwamura $^{1}$ and Jyoji Yamate ${ }^{1, *}$ \\ 1 Laboratory of Veterinary Pathology, Graduate School of Life and Environmental Sciences, \\ Osaka Prefecture University, 1-58 Rinku-Ourai-Kita, Izumisano City, Osaka 598-8531, Japan; \\ minto_0207@yahoo.ne.jp (M.N.); mrabiulkarim@bau.edu.bd (M.R.K.); izawa@vet.osakafu-u.ac.jp (T.I.); \\ kuwamura@vet.osakafu-u.ac.jp (M.K.) \\ 2 Department of Anatomy and Histology, Faculty of Veterinary Science, Bangladesh Agricultural University, \\ Mymensingh 2202, Bangladesh \\ * Correspondence: yamate@vet.osakafu-u.ac.jp; Tel.: +81-72-463-5334; Fax: +81-72-463-5346
}

check for updates

Citation: Nakagawa, M.; Karim, M.R.; Izawa, T.; Kuwamura, M.; Yamate, J. Immunophenotypical Characterization of M1/M2

Macrophages and Lymphocytes in Cisplatin-Induced Rat Progressive Renal Fibrosis. Cells 2021, 10, 257. https://doi.org/10.3390/cells10020257

Academic Editors:

Hans-Joachim Anders, Betty Diamond and Stefanie Steiger

Received: 17 December 2020

Accepted: 26 January 2021

Published: 28 January 2021

Publisher's Note: MDPI stays neutral with regard to jurisdictional claims in published maps and institutional affiliations.

Copyright: (c) 2021 by the authors. Licensee MDPI, Basel, Switzerland. This article is an open access article distributed under the terms and conditions of the Creative Commons Attribution (CC BY) license (https:/ / creativecommons.org/licenses/by/ $4.0 /)$.

\begin{abstract}
Renal fibrosis is regarded as the common final pathway leading to chronic kidney diseases; macrophages and myofibroblasts play important roles in the development of fibrosis. F344 rats were injected once with cisplatin (CDDP; $6 \mathrm{mg} / \mathrm{kg}$ BW) for renal lesions. Here, immunophenotypical characteristics of macrophages and lymphocytes in CDDP-induced rat renal lesions were investigated histopathologically; the CDDP-induced renal lesions consisted of tissue damage at the early-stage, worsen the damage and commencement of interstitial fibrosis at the mid-stage, and progressive fibrosis at the late stage; the KIM- 1 expression and $\alpha-\mathrm{SMA}^{+}$myofibroblast area reflected renal tubular damage/abnormal regeneration and renal interstitial fibrosis, respectively. $\mathrm{CD}^{+} 8^{+} \mathrm{M} 1$ macrophages began to increase at the mid-stage, with increased mRNA expressions of M1-related cytokines (INF- $\gamma$, TNF- $\alpha$ and IL-6), and then slightly decreased at the late-stage. CD163 ${ }^{+} \mathrm{M} 2$ macrophages showed a gradually increased number at the mid- and late-stages, accompanied by increased TGF- $\beta 1$ mRNA expression (a fibrogenic factor). Double immunofluorescence using fibrotic samples at the late-stage revealed that $62.0-78.0 \%$ of $\mathrm{CD}^{+} 8^{+} \mathrm{M} 1$ macrophages co-expressed $\mathrm{CD} 163$, indicating that M1/M2 macrophages may contribute to progressive renal fibrosis in cooperation; further, MHC class II-expressing macrophages had a tendency towards M1 polarization, whereas CD204-expressing macrophages towards $\mathrm{M} 2$ polarization. In addition, $\mathrm{CD}^{+}$and $\mathrm{CD} 8^{+} \mathrm{T}$ cells were increased at the late-stage. Collectively, progressive renal interstitial fibrosis may be developed by complicated mechanisms that arose via interaction of M1/M2 macrophages (inflammatory for M1 and antiinflammatory for M2) and T cells reacting to CD4 (for helper) and CD8 (for cytotoxicity). This study would provide some information on the pathogenesis of renal fibrosis based on inflammatory cells.
\end{abstract}

Keywords: cisplatin; M1/M2 macrophages; T lymphocytes; renal fibrosis; rats

\section{Introduction}

Regardless of initial causes, renal fibrosis is regarded as the common final pathway leading to chronic kidney diseases (CKD). The lesion is characterized histopathologically by an excessive accumulation and deposition of extracellular matrices (ECMs) in the interstitium. CKD ultimately results in renal dysfunction and end-stage renal failure, and the patients require dialysis or transplantation. The pathogenic mechanism of renal fibrosis should be clarified to prevent the progression.

Generally, macrophages and myofibroblasts play important roles in the development of fibrosis [1,2]. Myofibroblasts are mesenchymal cells capable of producing ECMs, and transforming growth factor- $\beta 1$ (TGF- $\beta 1$ ) is an important factor for the activation of myofibroblasts [3]. Macrophages produce TGF- $\beta 1$ [4]. In renal fibrosis, TGF- $\beta 1$ may promote tubular epithelial cell transdifferentiation into myofibroblasts (epithelial-mesenchymal 
transition; EMT) and enhance interstitial deposition of ECMs produced by myofibroblasts [5,6]. Therefore, macrophages are crucial in the pathogenesis of renal fibrosis [1]. Moreover, macrophages can contribute to the promotion or resolution of inflammation, removal of apoptotic cells by phagocytosis, and support of cell proliferation following tissue injury, indicating that macrophages have heterogeneous functions $[7,8]$.

Like Th1 and Th2 in T helper cells, macrophages are classified as M1 (classically activated) and M2 (alternatively activated) types [9]. M1 macrophages are induced by interferon- $\gamma($ IFN- $\gamma)$ and are characterized by active production of inflammatory cytokines, reactive nitrogen and oxygen intermediates, and promotion of Th1 response. In contrast, M2 macrophages are activated by IL-4 and associated with the resolution of inflammation and promotion of tissue remodeling and fibrosis [10]. Such macrophage plasticity is called M1/M2 polarization. Generally, the change of M1/M2 phenotypes of macrophages easily occurs in vitro; however, such events may not always be corresponding to that in pathological lesions in vivo because there are complicated factors in the body that should influence the functions of macrophages [11]. The histopathological/immunohistochemical approach of M1/M2-macrophages in vivo is very important.

To investigate the histopathological alterations of macrophages in pathological settings, therefore, the analysis of expression profiles of cell surface molecules are useful [9]. In the present study, by using renal fibrosis lesions induced in rats by cisplatin with renal toxicity, we performed the immunohistological phenotyping of macrophages using antibodies against cell surface molecules. CD68 is an antigen on lysosomal and endosomal membranes related to phagocytic activities [12], and its expression is regarded as an M1 macrophage marker [13,14]. CD163 is a receptor for hemoglobin-haptoglobin complexes and a member of the scavenger receptor cysteine-rich group B family. CD163 expression is regarded as a marker for M2 macrophages [15].

Although the appearance of macrophages was observed in rat renal fibrosis [16,17], the immunohistochemical characteristic of macrophages and lymphocytes have not yet been analyzed on the basis of the concept of M1/M2-macrophage polarization. The concept of M1/M2 polarization may be a key for understanding the pathogenesis of renal fibrosis, which would provide a basis for macrophage-centered diagnostic and therapeutic strategies [10]. We also investigated immunohistochemically the participation of lymphocytes, which may be related to M1/M2 polarization. Our results suggest that M1/M2 macrophages, as well as $\mathrm{T}$ cells, may contribute to the progressive renal fibrogenesis after tubular injury.

\section{Materials and Methods}

\subsection{Experimental Procedures}

Five-week-old male F344/DuCrj rats (106-146 g; Charles River Japan, Hino, Shiga, Japan) were housed in an animal room controlled at $22 \pm 3{ }^{\circ} \mathrm{C}$ and with a $12 \mathrm{~h}$ light-dark cycle and fed a standard diet (DC-8, CLEA Japan, Inc., Tokyo, Japan) and filtered tap water ad libitum. After one-week acclimatization, twenty-four rats received a single intraperitoneal injection of cisplatin (CDDP, cis-diamminedichloroplatinum; Nippon Kayaku Co. Ltd., Tokyo, Japan) at a dose of $6 \mathrm{mg} / \mathrm{kg}$ body weight. Three rats were examined on each of days 1, 3, 5, 7, 9, 12, 15 and 20 after CDDP injection. Three rats as control received an equal volume of physiological saline in the same manner and were examined on day 0 . All rats were euthanized under deep isoflurane anesthesia. Experimental protocols were performed according to the Institutional Guidelines for Animal Care and Use (Nos. 23-24 and 25-85) in Osaka Prefecture University.

\subsection{Histopathology and Immunohistochemistry}

Renal tissues were immediately fixed in 10\% neutral buffered formalin or periodatelysine-paraformaldehyde (PLP) solution and embedded in paraffin with AMeX (acetone, methyl benzoate and xylene) method [18]. Deparaffinized formalin-fixed sections were stained with hematoxylin and eosin (HE) for morphological examination and with the azan- 
Mallory stain for collagen deposition. Deparaffinized PLP-fixed sections were immunestained with primary antibodies and peroxidase-conjugated secondary antibody (Histofine simple stain MAX-PO; Nichirei, Tokyo, Japan). Details of the primary antibodies are listed in Table 1. Tissue sections were immunostained by Histostainer (Nichirei). Positive reactions were visualized with 3,3'-diaminobenzidine tetrahydrochloride (DAB; Nichirei), and the sections were then lightly counterstained with hematoxylin. For negative controls, tissue sections were treated with mouse or rabbit non-immunized serum instead of the primary antibody. Positive cells were counted in five randomly selected $40 \times$ fields in the corticomedullary junction in which interstitial fibrosis occurs in this rat model [19]. Areas of myofibroblasts reacting to $\alpha$-SMA (the most reliable marker for this cell type) were measured in five different fields of the corticomedullary junction using an image analyzing software (WinROOF, Mitani Corp., Fukui, Japan); because blood vessel-constituting smooth muscle react to $\alpha$-SMA [20], blood vessels were excluded for the analysis. In addition, a semiquantitative evaluation was made for interstitial fibrosis degree based on HE-stained and azan-Mallory-stained sections: no-fibrosis $(-)$, slight degree $(1+)$, moderate degree $(2+)$, severe degree $(3+)$ and more severe degree $(4+)$ in the affected corticomedullary region [20].

Table 1. Primary antibodies used for immunohistochemistry and immunofluorescence.

\begin{tabular}{|c|c|c|c|c|}
\hline Antibody & Type & Dilution & Pretreatment & Source \\
\hline CD163 (ED2) & Mouse monoclonal & $1 / 300$ & - & AbDSerotec, Oxford, UK \\
\hline CD68 (ED1) & Mouse monoclonal & $1 / 500$ & $10 \mu \mathrm{g} / \mathrm{mL}$ proteinase $\mathrm{K}, 20 \mathrm{~min}$ & Merck Millipore, MA, USA \\
\hline MHC class II (OX-6) & Mouse monoclonal & $1 / 300$ & Microwaving in citrate buffer, $20 \mathrm{~min}$ & AbDSerotec, Oxford, UK \\
\hline CD204 (SRA-E5) & Mouse monoclonal & $1 / 500$ & Microwaving in citrate buffer, $20 \mathrm{~min}$ & Transgenic Inc., Kumamoto, Japan \\
\hline$\alpha$-SMA & Mouse monoclonal & $1 / 1000$ & - & Dako, CA, USA \\
\hline CD4 & Mouse monoclonal & $1 / 2000$ & - & AbDSerotec, Oxford, UK \\
\hline CD8 & Mouse monoclonal & $1 / 200$ & - & AbDSerotec, Oxford, UK \\
\hline CD20 & Goat polyclonal & $1 / 200$ & Microwaving in citrate buffer, $20 \mathrm{~min}$ & Santa Cruz Biotechnology Inc., TX, USA \\
\hline KIM-1 & Goat polyclonal & $1 / 500$ & 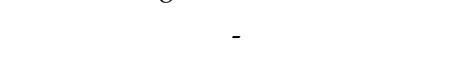 & $\begin{array}{l}\text { Immunology Consultants } \\
\text { Laboratory, OR, USA }\end{array}$ \\
\hline
\end{tabular}

\subsection{Double Immunofluorescence}

Ten- $\mu \mathrm{m}$ fresh-frozen sections from the kidney of control and CDDP-injected rats were used for double immunofluorescence; the antibody pairs were CD68 in combination with CD163, MHC class II and CD204, as well as CD163 with MHC class II and CD204. After fixation in cold PLP solution for CD68/CD204 combination and in cold acetone: methanol (1:1) solution for other combinations, the sections were incubated with $10 \%$ normal goat serum for $30 \mathrm{~min}$, followed by reaction with the primary antibody overnight at $4{ }^{\circ} \mathrm{C}$. After rinsing in PBS, the sections were incubated for $45 \mathrm{~min}$ with the goat anti-mouse IgG-conjugated with Alexa 568 (Invitrogen, Carlsbad, CA, USA). Then, the sections were incubated at room temperature for an hour with the following second primary antibodies labeled with fluorescent dye: Alexa 488-labeled CD68 (AbD Serotec, Oxford, UK) for CD68/CD163 and CD68/CD204 combinations; Alexa 488-labeled CD163 (AbD Serotec, Oxford, UK) for CD163/CD204; Alexa 488-labeled MHC class II (AbD Serotec, Oxford, UK) forCD68/MCH class II and CD163/MHC class II. The sections were cover-slipped with Vectashield ${ }^{\mathrm{TM}}$ mounting medium containing 4' ${ }^{\prime}$,6-diamidino-2-phenylindole (DAPI) (Vector Laboratories Inc., Burlingame, CA, USA) for nuclear staining and analyzed using a virtual slide scanner (VS-120; Olympus, Tokyo, Japan). Cells co-expressing CD68/CD163, CD68/MHC class II, CD163/MHC class II, CD68/CD204, and CD163/CD204 were counted in five randomly selected $40 \times$ fields of the corticomedullary junction.

\subsection{Reverse-Transcription Polymerase Chain Reaction (RT-PCR)}

Renal tissues collected from the corticomedullary junction were immediately immersed in RNAlater reagent (Qiagen, Hilden, Germany), kept overnight at $4{ }^{\circ} \mathrm{C}$ and stored at $-80^{\circ} \mathrm{C}$ until use. Total RNA was extracted from renal tissues using an SV Total RNA isolation system (Promega, Madison, WI, USA) according to the manufacturer's instructions. 
Two and a half $\mu$ g of total RNA was reverse-transcribed with Superscript VILO reverse transcriptase (Life Technologies, CA, USA). Real-time PCR was performed using Thunderbird Probe qPCR mix (Toyobo Co. Ltd., Osaka, Japan) with TaqMan gene expression assays (Life Technologies, Carlsbad, CA, USA) or Thunderbird SYBR qPCR mix (Toyobo) in a PikoReal real-time 96 PCR system (Thermo Scientific, Waltham, MA, USA). Taqman probes for IL-6 (Assay ID: Rn01410330_m1), IL-10 (Assay ID: Rn00563409_m1), IL-4 (Assay ID: Rn01456866_m1), and $\beta$-actin (Assay ID: Rn00667869_m1) were used. The primers used in the SYBR Green real-time PCR system are listed in Table 2. The data were calculated using the comparative $C_{t}$ method ( ${ }^{\Delta \Delta} C_{t}$ method) and normalized by the expression of $\beta$-actin mRNA as an internal control.

Table 2. Real-time RT-PCR primers.

\begin{tabular}{cccc}
\hline Primer & NCBI Symbol & Forward & Reverse \\
\hline IFN- $\gamma$ & Ifng & tcgcacctgatcactaacttcttc & cgactccttttccgcttcc \\
TNF- $\alpha$ & Tnf & tgcctcagcctcttctcattc & gctcctctgcttggtggttt \\
TGF- $\beta 1$ & Tgfb1 & cttcagctccacagagaagaactgc & cacgatcatgttggacaactgctcc \\
KIM-1 & Havcr1 & gtctgtattgttgccgagtgga & gttgtgggtcttgttggagga \\
$\beta$-actin & Actb & taaagacctctatgccaacac & ctcctgcttgctgatccacat \\
\hline IFN- $\gamma$-interferon- $\gamma$, TNF- $\alpha$-tumor necrosis factor- $\alpha$, TGF- $\beta 1-$ transforming growth factor- $\beta 1$, KIM-1-kidney \\
injury molecule- 1, NCBI-The National Center for Biotechnology Information.
\end{tabular}

\subsection{Statistical Analysis}

Data were statistically analyzed by the one-way analysis of variance (ANOVA) followed by Dunnett's multiple comparison test to investigate the kinetics against controls. Values of $p<0.05$ were considered significant from controls [14].

\section{Results}

\subsection{Histopathology of CDDP-Induced Rat Renal Lesion}

Control kidneys showed normal renal histological architecture (Figure 1A). On days 1 and 3 after CDDP injection, renal proximal tubular epithelial cells, especially at the S3 segment in the corticomedullary junction, underwent swelling with nuclear degeneration (Figure 1B); the degeneration was more clearly seen on day 3 . On days 5 and 7 , renal epithelial cells of the affected tubules were desquamated (Figure 1C,D), and then, the tubules were variously dilated, being lined by regenerating flattened or cuboidal epithelial cells. In addition, inflammatory cells began to be seen around the affected renal tubules and their lumina. On days 9 (Figure 1E), 12, and 15, the regenerating epithelial cells showed variable morphology (flattened, polyhedral, and cuboidal), indicating abnormal regeneration; around the variously dilated renal tubules, interstitial fibrosis was developed, accompanied by inflammatory cells. On day 20, interstitial fibrosis was more progressive, particularly around the renal tubules with incompletely regenerating epithelial cells (Figure 1F); inflammatory cells were continuously observed.

mRNA expression of kidney injury molecule-1 (KIM-1), a well-known biomarker for renal proximal tubule injury [21,22], was increased significantly on days 5-15 (Figure 2A), being consistent with histological tubular damage. The immunoreaction to KIM-1 was seen mainly in cuboidal or flattened epithelial cells in the damaged renal tubules (Figure 2B). The KIM-1 expression reflected the histopathological findings of renal tubular damages/ abnormal regeneration. 

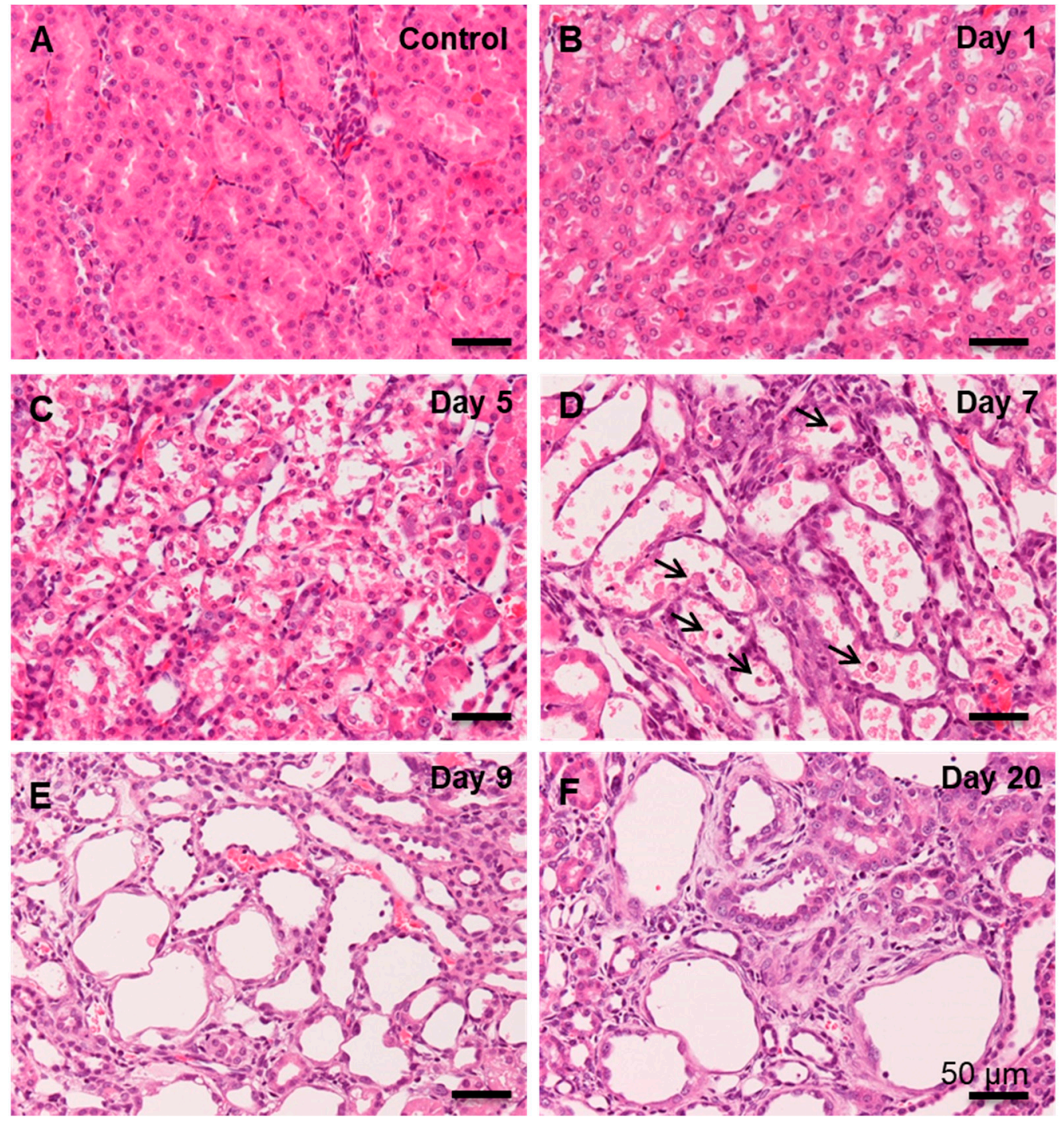

Figure 1. Histopathology of cisplatin (CDDP)-induced rat renal lesions. (A) In the control kidneys (fibrosis degree, - ), no significant change is observed. (B) On day 1 (fibrosis degree, -) following CDDP injection, renal proximal tubular epithelial cells in the corticomedullary junction show nuclear alterations. (C) On day 5 (fibrosis degree, 1+), the renal proximal tubular epithelial cells show swelling and desquamation. (D) On day 7 (fibrosis degree, 2+), the affected tubules are dilated, showing complete desquamation, and lined partly by regenerating epithelial cells; infiltration of inflammatory cells (arrow) are seen in the injured lumina. (E) On day 9 (fibrosis degree, 3+), fibrosis is observed in the interstitium around the affected tubules with variously dilated lumen. (F) On day 20 (fibrosis degree, 4+), the damaged renal tubules lined by incompletely regenerating epithelial cells and fibrosis are seen around these tubules. HE stain, bar $=50 \mu \mathrm{m}$.

\subsection{Collagen Deposition and Myofibroblast Appearance in CDDP-Induced Rat Renal Lesion}

In the kidneys of control and on days 1 and 3 , interstitial fibrosis was not seen (fibrosis degree, - ) in the affected corticomedullary junction. Collagen fibers stained blue with the azan-Mallory method began to be gradually seen around the affected renal tubules on days $5(-\sim 1+), 7(1+\sim 2+), 9(2+\sim 3+)$, and $12(2+\sim 3+)$; the deposition degree became gradually severe on days $15(3+\sim 4+)$ and $20(3+\sim 4+)$ (Figure $3 \mathrm{~A}, \mathrm{~B})$. Immunohistochemically, on day $7, \alpha$-SMA ${ }^{+}$myofibroblasts began to clearly appear in the interstitium around the affected renal tubules lined by abnormal regenerating epithelial cells. On day 9 onwards, the area of $\alpha-\mathrm{SMA}^{+}$myofibroblasts showed a significant increase with a peak on day 15 (Figure 
3C,D), in comparison to controls. The area of $\alpha$-SMA-positive myofibroblasts sufficiently reflected the degrees of progressive interstitial fibrosis.

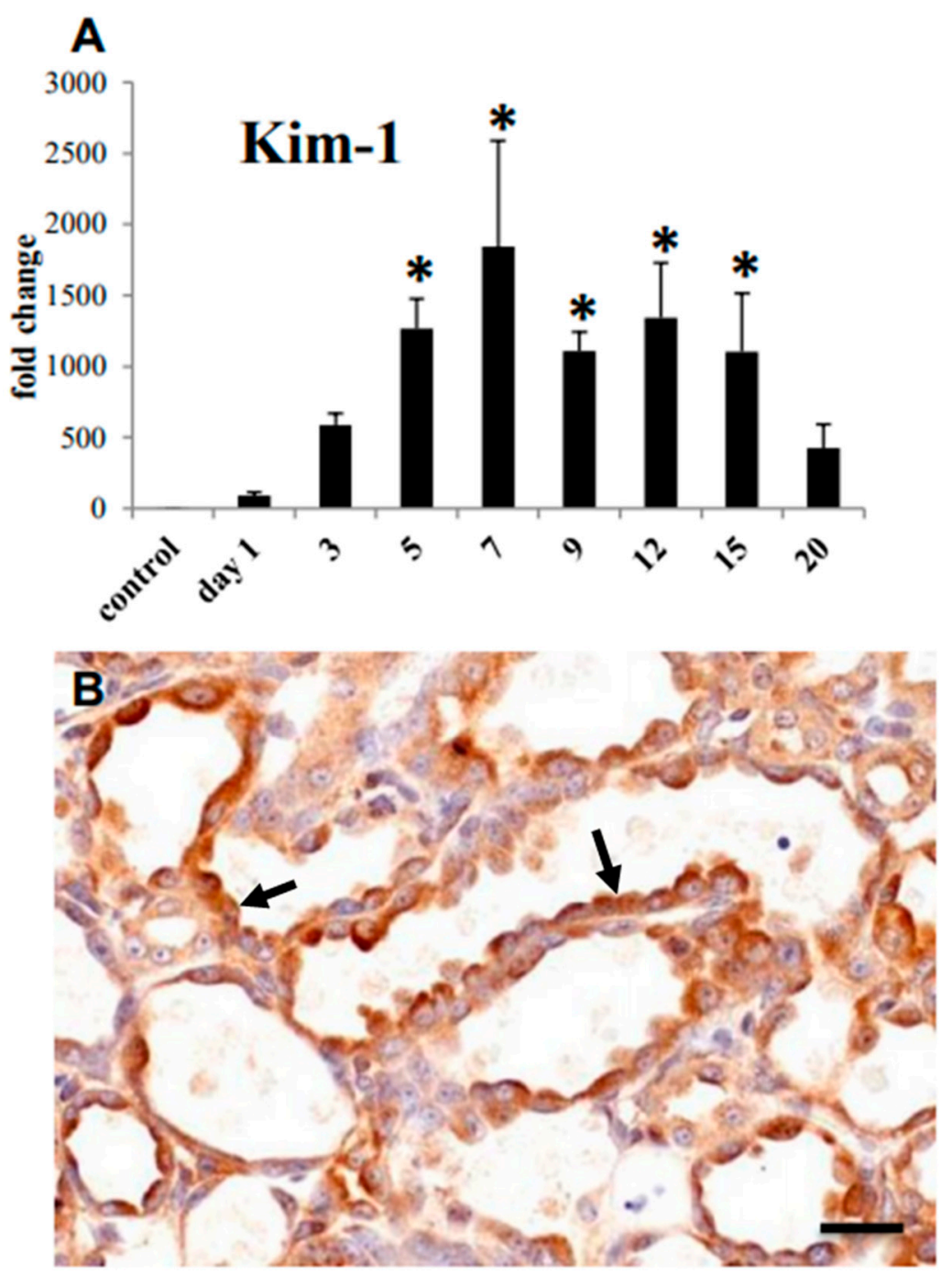

Figure 2. CDDP-induced renal lesions in rats. (A) mRNA expression of kidney injury molecule-1 (KIM-1) in the control and CDDP-injected rats on days 1 to 20; Dunnett's test, *, significantly different from controls at $p<0.05$. (B) Immunohistochemistry for KIM-1; arrows indicated immune-positive regenerating epithelial cells of the affected tubules on day 9 . Bar $=50 \mu \mathrm{m}$.

Although the lesions were overlapping to each other, based on the renal tubular damage/interstitial fibrosis, the renal failure induced by CDDP injection were regarded as following: tissue damage/cell injury at the early-stage on days 1-3, abnormal regeneration of damaged tubules and commencement of fibrosis at the mid-stage on days 5-9, and progressive fibrosis at the late-stage on days 12-20.

\subsection{Macrophages Appearing in CDDP-Induced Rat Renal Lesion}

Along with $\mathrm{CD}^{+} 8^{+}(\mathrm{M} 1)$ and $\mathrm{CD} 163^{+}(\mathrm{M} 2)$ macrophages, macrophages reacting to MHC class II and CD204 were evaluated in the CDDP-induced renal lesion.

\subsection{1. $\mathrm{CD}^{+} 8^{+}$Macrophages}

In the control and affected kidneys on days 1 and 3, a small number of $\mathrm{CD}^{+}$ macrophages were seen in the corticomedullary junction (Figures $4 \mathrm{~A}$ and $5 \mathrm{~A}$ ). The number of $\mathrm{CD}_{6} 8^{+}$macrophages increased significantly from day 5 onwards, with a peak on day 9 
(Figure 4A). $\mathrm{CD}^{+} 8^{+}$macrophages were distributed around the damaged renal tubules and within their lumen (Figure 5B,C).
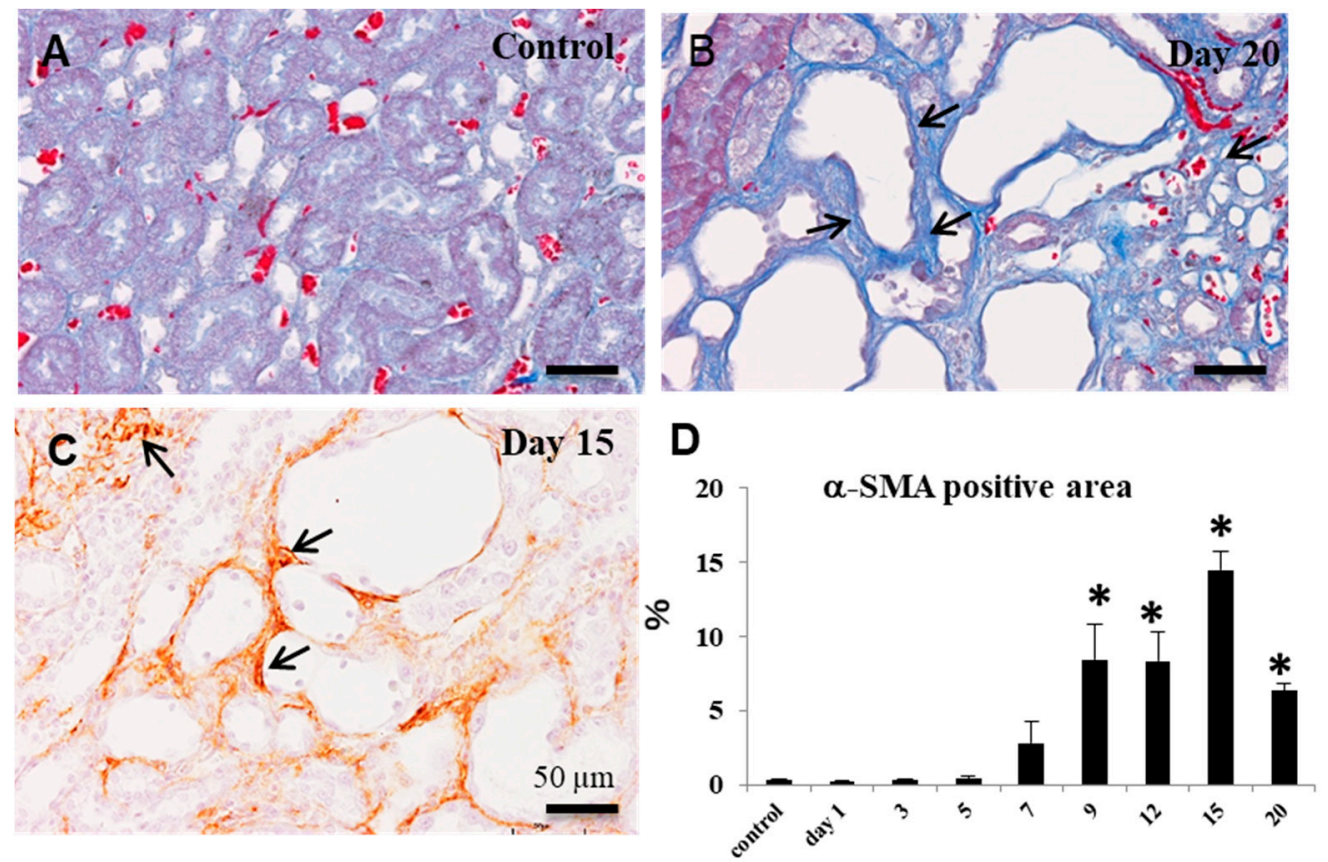

Figure 3. Evaluation of interstitial fibrosis of CDDP-induced rat renal lesions. (A) The azan-Mallory stain; in the control kidneys, collagen fibers are not seen in the interstitium (fibrosis degree, - ). (B) The azan-Mallory stain; on day 20, severe fibrosis (fibrosis degree, $4+$ ) (arrows) is seen in the interstitium. (C) Immunohistochemistry for $\alpha$-smooth muscle action ( $\alpha$-SMA); $\alpha$-SMA-positive myofibroblasts are seen in the increased fibrosis (fibrosis degree, 4+) (arrows). Bar $=50 \mu \mathrm{m}$. (D) The percentage of $\alpha$-SMA-positive area in the control and CDDP-injected rats on days 1 to 20; Dunnett's test, ${ }^{*}$, significantly different from controls at $p<0.05$.

A

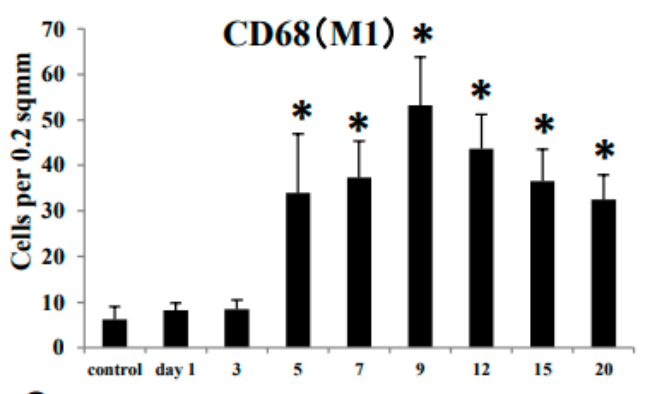

C

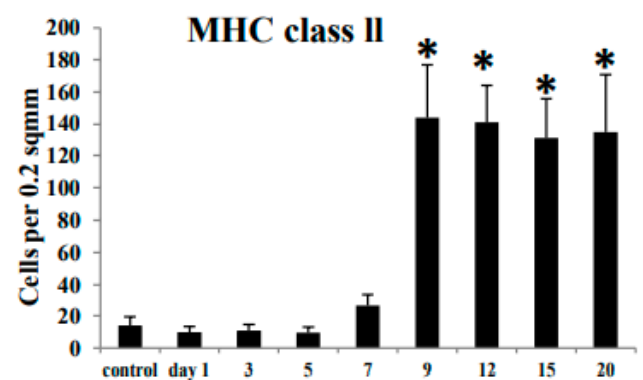

B

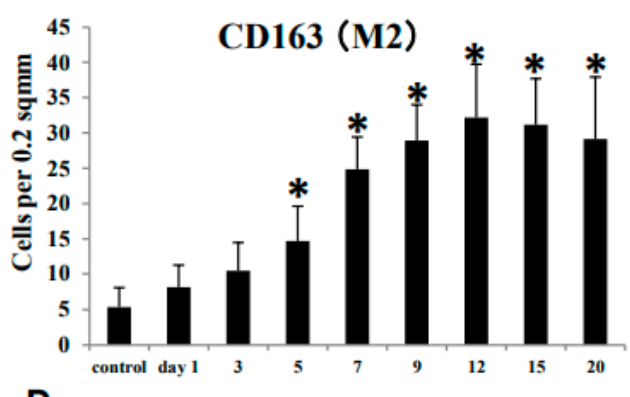

D

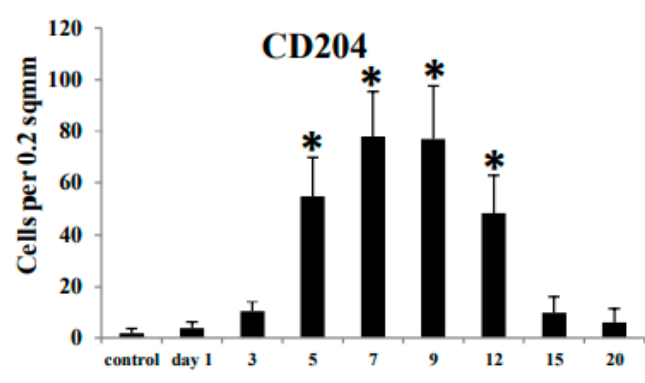

Figure 4. The number of macrophages reacting to CD68 (A, for M1), CD163 (B, for M2), MHC class II (C), and CD204 (D) in the control and CDDP-treated kidney on days 1-20. Note that the kinetics of these macrophages in comparison to controls differ from each other. Dunnett's test, ${ }^{*}$, significantly different from controls at $p<0.05$. 


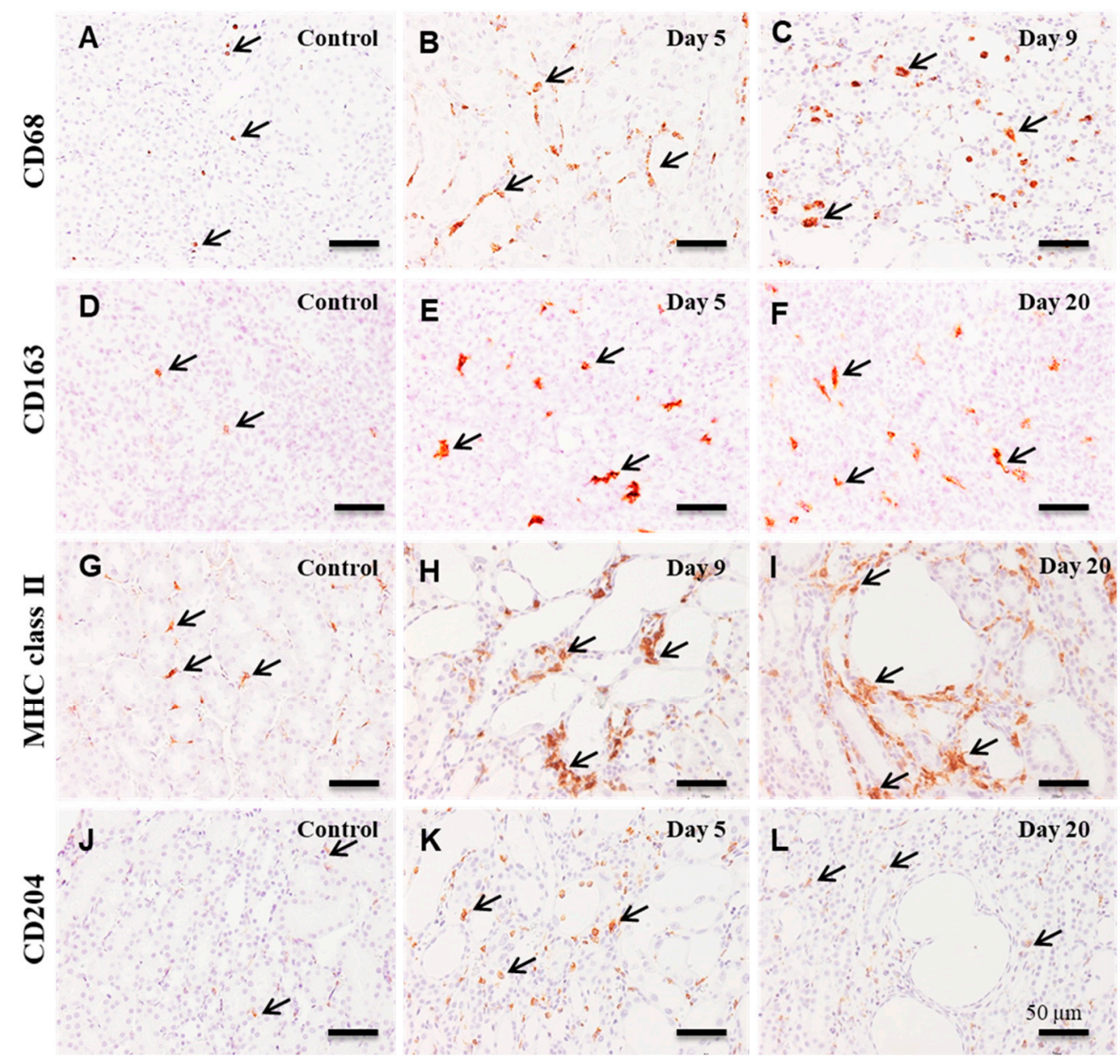

Figure 5. Immunohistochemistry for CD68 (A-C), CD163 (D-F), MHC class II (G-I), and CD204 (J-L) in the control and CDDP-treated kidneys. A few $\mathrm{CD} 68^{+}$macrophages (arrows) are seen in the corticomedullary junction of control kidneys (A), whereas many macrophages reacting CD68 (arrows) are present around the affected renal tubules on days 5 (B) and 9 (C). In contrast to control (D), many CD163 ${ }^{+}$macrophages (arrows) are seen on days 5 (E) and 20 (F). Increased numbers of MHC class $\mathrm{II}^{+}$macrophages (arrows) are seen exclusively around the affected renal tubules on days $9(\mathbf{H})$ and $20(\mathbf{I})$, in contrast to control $(\mathbf{G})$. Only a few CD204 ${ }^{+}$macrophages are present in the control (J) and on day $20(\mathbf{L})$, whereas, on day $5, \mathrm{CD} 204^{+}$macrophages are increased $(\mathbf{K})$. Note that there are differences in the distribution and location of these macrophages from each other. Counterstained with hematoxylin. Bar $=50 \mu \mathrm{m}$.

\subsection{2. $\mathrm{CD}_{163^{+}}$Macrophages}

A few $\mathrm{CD}_{163^{+}}$macrophages were observed in the control and affected kidneys on days 1 and 3 (Figures 4B and 5D). The number of CD163 $3^{+}$macrophages was significantly increased on days 5 to 20; that is, a large number of $\mathrm{CD} 163^{+}$cells were distributed mainly in the interstitium of the renal medulla (Figure $5 \mathrm{E}, \mathrm{F}$ ); the positive cells were rarely seen within the damaged renal lumen.

\subsubsection{MHC Class $\mathrm{II}^{+}$Macrophages}

A few MHC class $\mathrm{II}^{+}$macrophages were seen in the control and affected kidneys on days 1 to 7 (Figures $4 \mathrm{C}$ and 5G). On day 9, the number of MHC class $\mathrm{II}^{+}$macrophages was quickly increased in the corticomedullary junction, showing the statistical significance (Figures $4 \mathrm{C}$ and $5 \mathrm{H}$ ). On days 12 to 20, the number of $\mathrm{MHC}$ class $\mathrm{II}^{+}$macrophages retained increased, and the positive cells were seen exclusively around the damaged renal tubules (Figure 5I). 


\subsubsection{CD204 ${ }^{+}$Macrophages}

In the control and affected kidneys on days 1 and 3, only a few $\mathrm{CD} 204^{+}$macrophages were seen (Figures 4D and 5J). The number of CD204 ${ }^{+}$macrophages was significantly increased on days 5 to 12 (Figures $4 \mathrm{D}$ and $5 \mathrm{~K}$ ). The number was then decreased to the control level on days 15 and 20 (Figures $4 \mathrm{D}$ and 5L). CD204 ${ }^{+}$macrophages were seen mainly around the affected renal tubules and within their lumen (Figure 5K).

\subsection{M1/M2 Macrophage Polarization in CDDP-Induced Rat Renal Lesion}

In order to investigate the macrophage polarization for M1 (CD68) or M2 (CD163) type, double immunofluorescence with combinations of CD163/CD68 (Figure 6A), CD68/MHC class II (Figure 6B), CD163/MHC class II (Figure 6C), CD68/CD204 (Figure 6D), and CD163/CD204 (Figure 6E) were conducted in the affected kidneys at the late-stage, because progressive fibrosis with increasing macrophage number was seen mainly on days 12 , 15 and 20. On the examination points, the percentage of $\mathrm{CD}_{163^{+}} / \mathrm{CD}^{+} 8^{+}$cells to $\mathrm{CD} 68^{+}$ cells was from 62.0 to $78.0 \%$; $\mathrm{CD}^{+} / \mathrm{MHC}$ class $\mathrm{II}^{+}$cells to $\mathrm{MHC}$ class $\mathrm{II}^{+}$cells ranged in percentage from 33.2 to $80.3 \%$, whereas $\mathrm{CD} 163^{+} / \mathrm{MHC}$ class $\mathrm{II}^{+}$cells to $\mathrm{MHC}$ class $\mathrm{II}^{+}$cells from 9.8 to $16.4 \%$, indicating the polarization of $\mathrm{MHC}$ class $\mathrm{II}^{+}$macrophages toward $\mathrm{CD} 68^{+}$ M1 type; $\mathrm{CD}^{+} 8^{+} / \mathrm{CD} 204^{+}$cells to $\mathrm{CD} 204^{+}$cells ranged in percentage from 25.0 to $45.5 \%$, whereas $\mathrm{CD}_{163}{ }^{+} / \mathrm{CD} 204^{+}$cells CD204 ${ }^{+}$cells from 71.2 to $80.0 \%$, indicating that $\mathrm{CD} 204^{+}$ macrophage had a tendency to $\mathrm{CD} 163^{+} \mathrm{M} 2$ polarization.

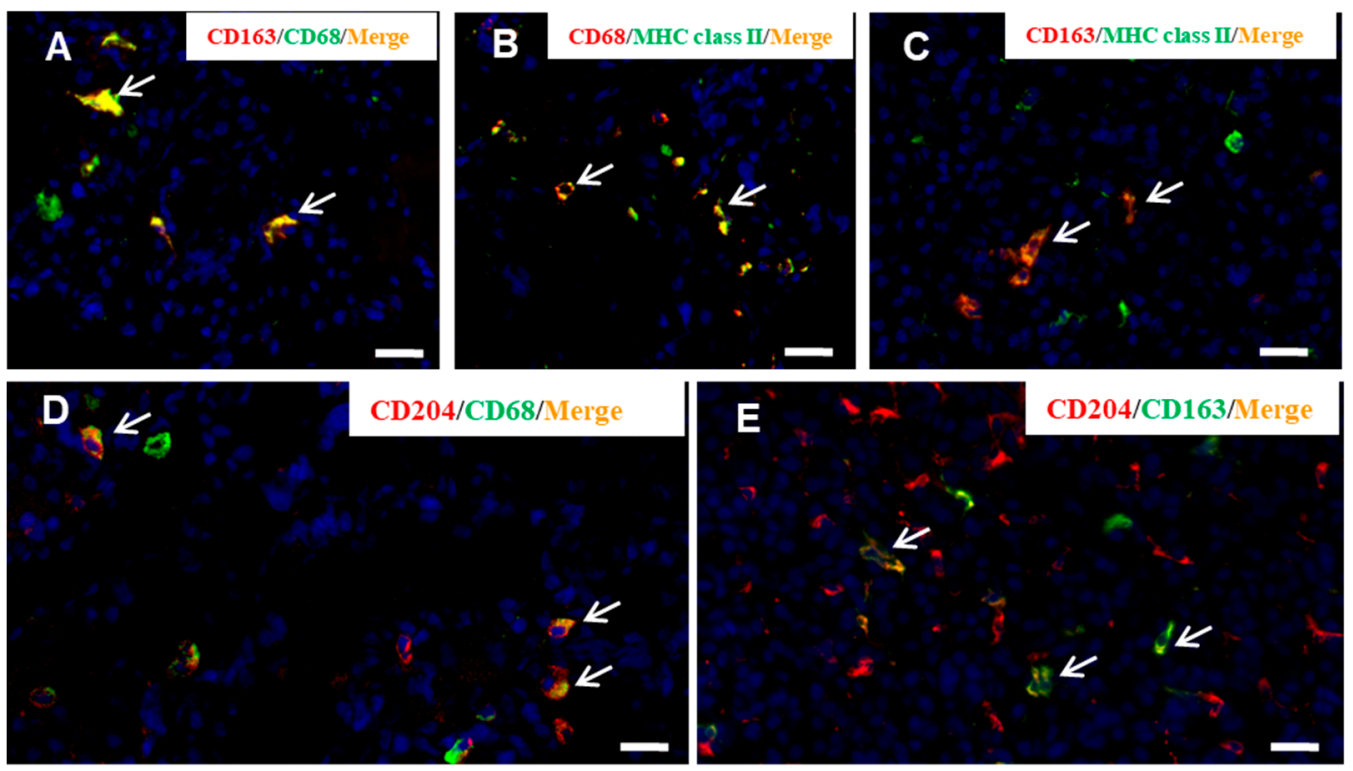

Figure 6. Double immunofluorescence for CD163/CD68 (A), CD68/MHC class II (B), CD168/MHC class II (C), CD68/CD204 (D), and CD163/CD204 (E) in CDDP-induced renal lesions on day 9. Yellow color (arrows) indicates double-positive reactions. Blue indicates nuclei stained with 4',6-diamino-2-phenylindole (DAPI). Bar $=20 \mu \mathrm{m}$.

\subsection{M1- and M2-Related Factors in CDDP-Induced Rat Renal Lesion}

Renal expression of IFN- $\gamma$, TNF- $\alpha$, and IL- 6 as M1-related inflammatory factors and TGF- $\beta$, IL-10, and IL-4 as M2-related anti-inflammatory factors [1,23] was analyzed.

mRNAs of IFN- $\gamma$ (Figure 7A) and TNF- $\alpha$ (Figure 7B) significantly increased on days

5 to 15 and on days 5 and 7, respectively. IL- 6 mRNA (Figure 7C) increased earlier than that of IFN- $\gamma$ and TNF- $\alpha$; the expression significantly increased on days 3,5 and 9. TGF- $\beta 1$ mRNA significantly increased on days 7 to 20 (Figure 7D). mRNAs of IL-10 and IL-4 did not show any significant changes. 
A

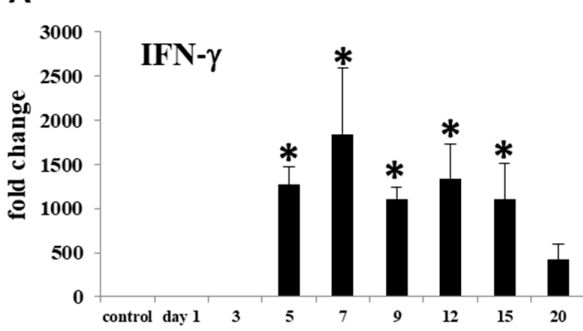

C

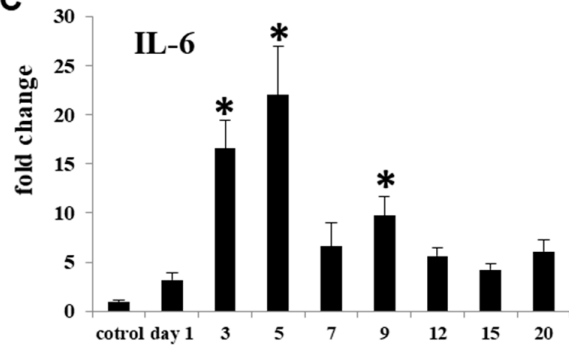

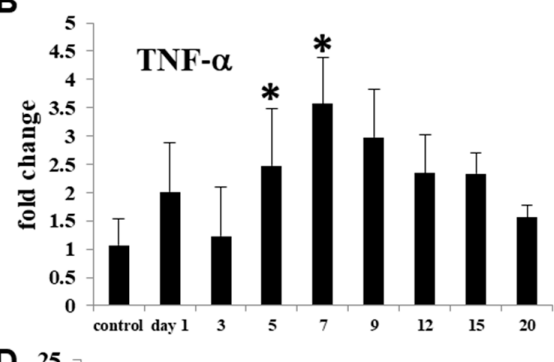

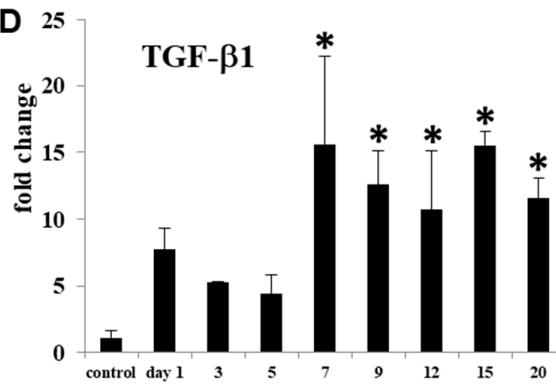

Figure 7. mRNA expressions for M1-related factors such as IFN- $\gamma$ (A), TNF- $\alpha$ (B) and IL-6 (C), and for M2-related factor TGF- $\beta 1$ (D) in the control and CDDP-treated kidneys on days 1-20. Expression levels were normalized by $\beta$-actin RNA level. Dunnett's test, ${ }^{*}$, significantly different from controls at $p<0.05$.

\subsection{Lymphocyte Appearance in CDDP-Induced Rat Renal Lesion}

\subsubsection{CD4 ${ }^{+}$T Lymphocytes}

In the control and affected kidneys on day 1 , a small number of $\mathrm{CD}^{+} \mathrm{T}$ cells were sporadically seen without showing significant changes (Figures $8 \mathrm{~A}$ and $9 \mathrm{~A}$ ). The number of $\mathrm{CD}^{+} \mathrm{T}$ cells was significantly increased on days 3 to 20; in particular, the markedly increased number retained on day 9 onwards (Figure 8A), and the positive cells appeared mainly around the damaged renal tubules (Figure 9B,C).

A
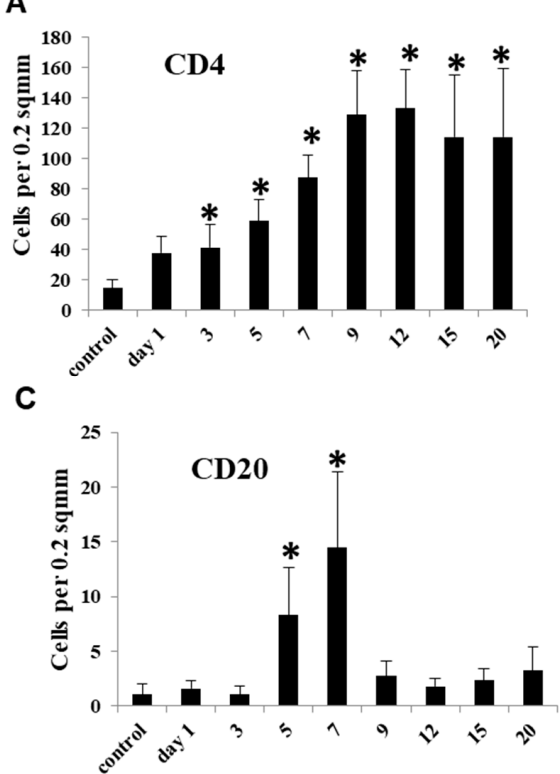

B

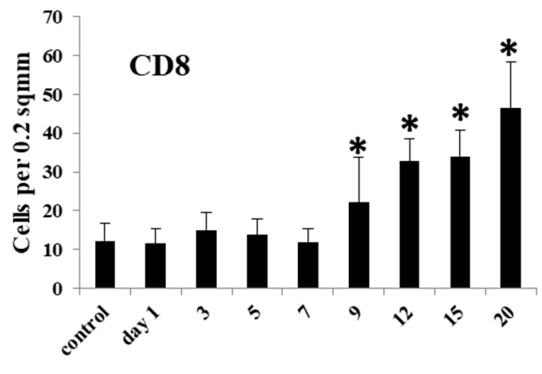

Figure 8. The number of lymphocytes reacting to CD4 (A), CD8 (B) and CD20 (C) in the control and CDDP-treated kidneys on days 1-20. Note that the kinetics of these lymphocytes to controls differs from each other. Dunnett's test, ${ }^{*}$, significantly different from controls at $p<0.05$. 


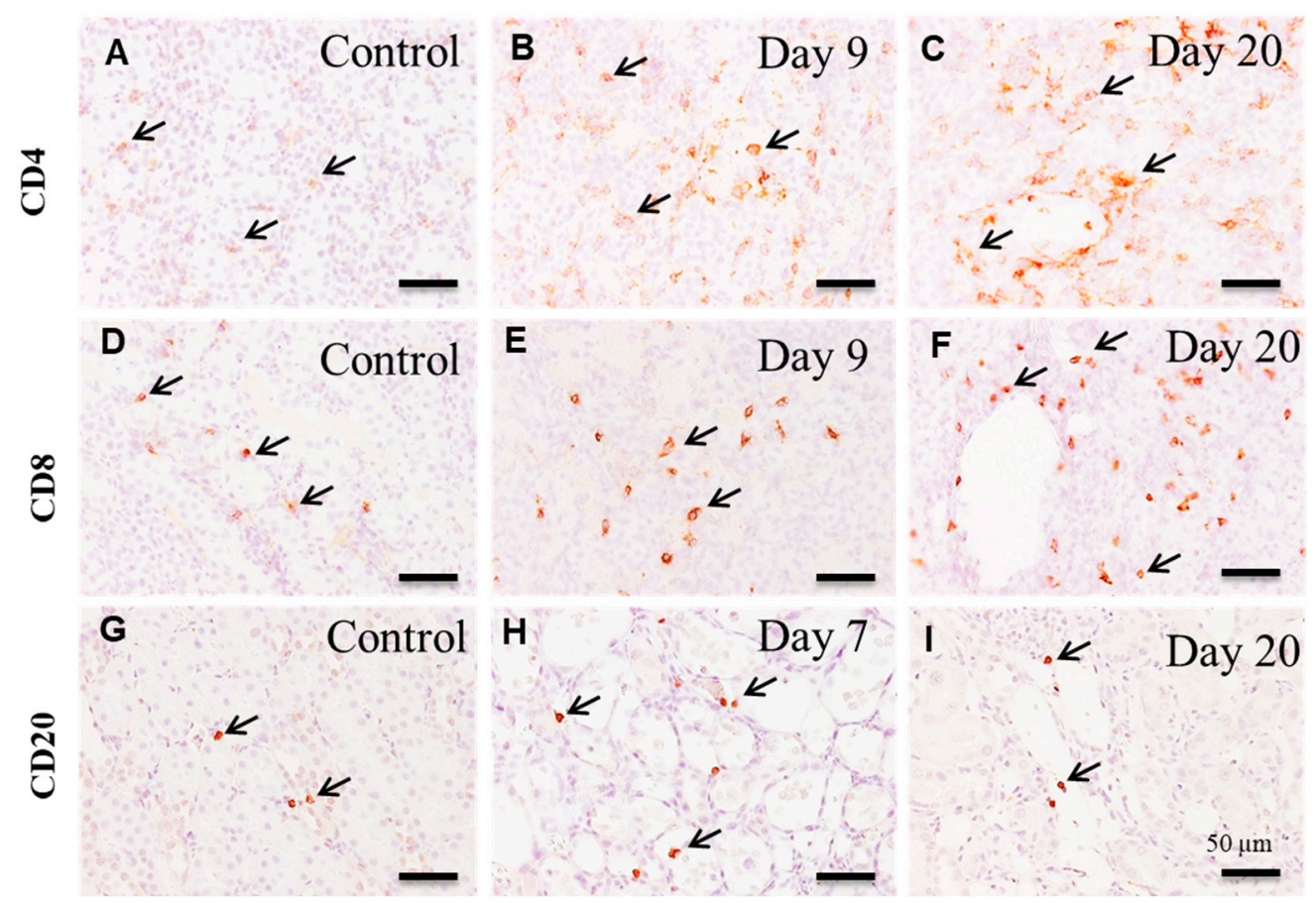

Figure 9. Immunohistochemistry for CD4 (A-C), CD8 (D-F) and CD20 (G-I) in the control and CDDP-treated kidneys. In contrast to control (A), the number of $\mathrm{CD}^{+} \mathrm{T}$ lymphocytes(arrows) are increased on day $9(\mathbf{B})$ and aggregated $\mathrm{CD}^{+} \mathrm{T}$ cells (arrows) are seen around the affected renal tubules on day 20 (C). In contrast to control (D), CD8 ${ }^{+} \mathrm{T}$ cells (arrows) are increased on day 9 (E) and tend to aggregate around the affected renal tubules on day $20(\mathbf{F})$. In contrast to control $(\mathbf{G})$ and on day 20 (I), CD20 $0^{+}$B cells (arrows) are increased on day $7(\mathbf{H})$. Note that the distributions of these lymphocytes are different from each other. Counterstained with hematoxylin. Bar $=50 \mu \mathrm{m}$.

\subsection{2. $\mathrm{CD} 8^{+} \mathrm{T}$ Lymphocytes}

A few $\mathrm{CD} 8^{+} \mathrm{T}$ cells were seen in the control and affected kidneys on days 1-7, without significant changes (Figures $8 \mathrm{~B}$ and $9 \mathrm{D}$ ). Then, the number of $\mathrm{CD}^{+} \mathrm{T}$ cells showed a significant increase on days 9 to 20 (Figure $8 \mathrm{~B}$ ), and the positive cells were observed diffusely or focally around the damaged renal tubules (Figure 9E,F).

\subsubsection{CD20+ B Lymphocytes}

There were a small number of $\mathrm{CD} 20^{+} \mathrm{B}$ cells in the control and affected kidneys on days 1 and 3 (Figures $8 \mathrm{C}$ and $9 \mathrm{G}$ ). On days 5 and 7, the number of $\mathrm{CD} 20^{+} \mathrm{B}$ cells was significantly increased, showing a transient increase (Figures $8 \mathrm{C}$ and $9 \mathrm{H}$ ); however, the positive cell number was much less than that of $\mathrm{CD}^{+}$and $\mathrm{CD} 8^{+} \mathrm{T}$ cells. Thereafter, $\mathrm{CD} 20^{+}$ B cells were suddenly decreased to control levels on day 9 onwards (Figures $8 \mathrm{C}$ and $9 \mathrm{I}$ ).

\section{Discussion}

Experimentally induced rat renal fibrosis by CDDP injection has been used, mainly focusing on injured renal tubules and interstitial fibrosis $[16,19,20,24]$. The degrees and progression of interstitial fibrosis seen in the present rat renal failure were generally corresponding to those reported previously $[16,20]$. Renal fibrosis is characterized by the appearance of myofibroblasts [20]. The myofibroblasts reacting to $\alpha$-SMA was increased with advancing renal fibrosis in CDDP-injected rats [20], as seen in the present study. It is reported that there are myofibroblasts co-expressing to $\alpha$-SMA/vimentin or $\alpha$-SMA/desmin, indicating that myofibroblasts show various cytoskeletons; in addition, renal myofibroblasts express Thy-1 (CD90; immature stromal stem marker) [20]. Because the pericytes show a positive reaction to Thy-1, renal myofibroblasts may be originated partly from immature mesenchymal cells [20]. Further, the myofibroblasts may be developed via the 
EMT evoked from incompletely regenerating renal tubules [24]. The CDDP-induced rat renal fibrosis resembles those of human renal progressive fibrosis like CKD [20].

The pathogenesis of renal fibrosis remains to be fully investigated [25], particularly in terms of inflammatory cell reaction. In human CKD and renal failure animal models, macrophage infiltration is a common pathological feature [26]. Macrophages may play an important role in the pathogenesis. The present immunohistochemical results in CDDPinduced rat renal lesions showed that M1 macrophages reacting to CD68 began to increase on day 5, with a peak on day 9; thereafter, the $\mathrm{CD} 68^{+} \mathrm{M} 1$ macrophages gradually decreased until day 20. Expression of M1-related inflammatory factors such as IFN- $\gamma$, TNF- $\alpha$ and IL- 6 began to increase on days 3 and 5 and retained increased mainly at the mid-stage. The appearance of $\mathrm{CD}^{+} 8^{+} \mathrm{M} 1$ macrophages generally corresponded to increased M1-related inflammatory factors. Histopathologically, the injury of renal epithelial cells by CDDP began to be seen clearly on day 3 , and the injury lesions became greater in severity on days 5 and 7; the damaged renal tubules were characterized by swelling, necrosis and desquamation of epithelial cells $[19,20]$. Additionally, mRNA expression of KIM-1, a marker of renal injury [27], began to significantly increase on day 5, with the continuous expression until day 15; KIM-1 immuno-expression was seen mainly in abnormally regenerating epithelial cells of damaged tubules. Collectively, $\mathrm{CD}^{+} 8^{+}$macrophages appearing mainly at the mid-stage may participate in the progressive renal injury which was caused initially by CDDP. It is known that M1 macrophages promote tissue injury by producing inflammatory factors $[9,28]$.

Generally, fibrosis after tissue injury is regarded as a healing process [25]. In the present renal failure by CDDP, renal interstitial fibrosis began to be seen clearly on days 7 (fibrosis degree $1+\sim 2+$ ) and 9 (fibrosis degree $2+\sim 3+$ ) and subsequently occurred progressively on days 12 (fibrosis degree $2+\sim 3+$ ), 15 (fibrosis degree $3+\sim 4+$ ) and day 20 (fibrosis degree $3+\sim 4+$ ). The interstitial fibrosis degrees corresponded to the appearance of $\alpha$ $\mathrm{SMA}^{+}$myofibroblasts. Interestingly, $\mathrm{CD}_{163}{ }^{+} \mathrm{M} 2$ macrophages began to increase on day 5 and retained the increased number until day 20. It is considered that in contrast to M1 macrophages, M2 macrophages have roles of anti-inflammatory functions and fibrogenesis $[9,25]$. TGF- $\beta 1$, which is the most powerful factor for fibrogenesis $[3,25]$, was increased on days 7 to 20 , being generally similar to the appearance of $\mathrm{CD} 163^{+} \mathrm{M} 2$ macrophages. Collectively, progressive renal interstitial fibrosis in the present study at the mid and latestages on days 9 to 20 may be associated with the appearance of $\mathrm{CD} 163^{+} \mathrm{M} 2$ macrophages and increased TGF- $\beta 1$.

It has been considered that M1/M2 macrophage phenotypes could be interchangeable depending on microenvironments $[7,10,14]$. Double immunofluorescence with CD68/CD163 showed that $\mathrm{CD}^{+} 8^{+}$macrophages, which simultaneously expressed CD163, were seen at the late-stage with the development of fibrosis. It is likely that M1 macrophages could undergo a phenotypic switch towards M2 macrophages. The appearance of $\mathrm{CD} 68^{+} / \mathrm{CD} 163^{+}$ macrophages with both phenotypes of M1/M2 types may have attributed to progressive renal damage by showing biphasic functions of tissue injury (for M1 type) and fibrosis (for M2 type). Previously, it was reported that M1-/M2-macrophages contribute in a cooperated manner to the development of pseudo-lobules (surrounded by fibrotic lesions) in chemically induced rat cirrhosis [13]. In order to investigate the M1/M2 polarization of MHC class $\mathrm{II}^{+}$and CD204 ${ }^{+}$macrophages, the double immunofluorescence with combinations of CD68/MHC class II and CD163/MHC class II or CD68/CD204 and CD163/CD204 were conducted. Particularly, at the end stages on days 9 to 20, the number of MHC class $\mathrm{II}^{+}$ macrophages expressing concomitantly CD68 was much greater than that of CD163 ${ }^{+} / \mathrm{MHC}$ class $\mathrm{II}^{+}$macrophages. Apparently, MHC class $\mathrm{II}^{+}$macrophages showed a tendency of M1 polarization. On the contrary, the number of $\mathrm{CD} 68^{+} / \mathrm{CD} 204^{+}$macrophages at the latestage was much lower than that of $\mathrm{CD} 163^{+} / \mathrm{CD} 204^{+}$macrophages, indicating that $\mathrm{CD} 204^{+}$ macrophages may have functional properties towards M2 polarization. It is reported that MHC class II antigen expression may be included in the M1 macrophage pathway, 
whereas M2 macrophage phenotype is also associated with scavenger receptors such as CD204 [1,29].

Besides macrophage infiltration, the recruitment of lymphocytes is another important event in renal interstitial fibrosis [22]. $\mathrm{CD}^{+} \mathrm{T}$ cells were increased on days 3 to 20, with the plateau on day 9 onwards. On day 9 onwards, MHC class $\mathrm{II}^{+}$macrophages began to be concomitantly increased. More interestingly, $\mathrm{CD}^{+} \mathrm{T}$ cells and $\mathrm{MHC}$ class $\mathrm{II}^{+}$macrophages tended to appear around the damaged renal tubules at the late-stage. Because $\mathrm{CD}^{+}{ }^{+} \mathrm{T}$ cells

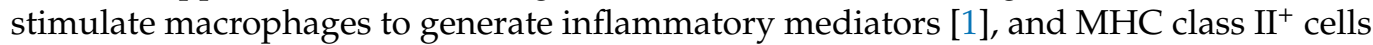
are known to present the processed antigens to $\mathrm{CD}^{+} \mathrm{T}$ cells, $\mathrm{CD} 4^{+} \mathrm{T}$ cells may act with the relation of $\mathrm{MHC}$ class $\mathrm{II}^{+}$macrophages with the polarization into M1 macrophages. In fact, it is reported that $\mathrm{CD}^{+} \mathrm{T}$ cells contribute to the progress of renal fibrosis $[30,31]$.

$\mathrm{CD}^{+} \mathrm{T}$ cells also began to be increased from day 9 onwards. M2 macrophages are reported to suppress $\mathrm{CD}^{+} \mathrm{T}$ cell-mediated cytotoxicity to tubular cells by producing antiinflammatory cytokines [26]. The appearance of M2 macrophages may be a pathological event against the cytotoxicity by $\mathrm{CD}^{+} \mathrm{T}$ cells. Apparently, the present progressive renal fibrosis seen at the late-stage may be developed by the attendance of complicated cell types: presumably, cooperation between $\mathrm{M} 1$ macrophages and $\mathrm{CD}^{+} \mathrm{T}$ cells, and confrontation between $\mathrm{M} 2$ macrophages and $\mathrm{CD}^{+} \mathrm{T}$ cells.

The number of $\mathrm{CD} 20^{+} \mathrm{B}$ cells was transiently increased at the mid-stage on days 5 and 7. A study on mouse unilateral ureteral obstruction model showed that the earlystage accumulation of B cells in the affected kidney accelerated monocyte/macrophage mobilization and infiltration, leading to aggravated fibrosis [32]. The significance of $\mathrm{CD} 20^{+} \mathrm{B}$ cells remains to be investigated because the number of $\mathrm{CD} 20^{+} \mathrm{B}$ cells was much lower, as compared with $\mathrm{T}$ cells reacting to CD4 and CD8.

In conclusion, the present study demonstrated the possible pathogenesis of CDDPinduced rat renal interstitial fibrosis, based on the immunohistochemical analyses of M1/M2 macrophage polarization and appearance of lymphocytes. CD68 $8^{+} \mathrm{M} 1$ macrophages appeared with increased M1-related factors relating to tissue damage. In progressive renal interstitial fibrosis developed at the late-stage after tissue damage, an increased number of $\mathrm{CD}_{163^{+}} \mathrm{M} 2$ macrophages were consistently seen, and there were macrophages reacting simultaneously to both CD68 and CD163; furthermore, $\mathrm{MHC}$ class $\mathrm{II}^{+}$macrophages showed a polarization into M1 macrophages, whereas CD204 ${ }^{+}$macrophages were toward M2 polarization. Along with M1/M2 macrophages, $\mathrm{CD}^{+}$and $\mathrm{CD}^{+} \mathrm{T}$ cells showed an increase at the late-stage. The progressive fibrosis may be developed by complicated functions that arose via the interaction of M1/M2 macrophages (inflammatory M1 and antiinflammatory M2) and T cells reacting to CD4 (for helper) and CD8 (for cytotoxicity). It is interesting to investigate more detailed functions of macrophages and lymphocytes, as well as the mutual relationship of these cells, in progressive renal fibrosis, particularly by using the technique of macrophage depletion, because there were somewhat differences in the distribution and kinetics of these inflammatory cells; studies on inflammatory cells would contribute to therapeutic strategies for CKD. This is the first trial of detained analyses (such as M1/M2 macrophage polarization) of inflammatory cells in vivo in CDDP-induced rat renal fibrosis.

Author Contributions: M.N., T.I., M.K., and J.Y. conceived the project; M.N., T.I., and M.R.K. performed the experiments; M.N., M.R.K. and J.Y. wrote the manuscript. All authors have read and agreed to the published version of the manuscript.

Funding: This work was supported partly by the JSPS KAKENHI Grant Numbers 26292152 and 19H03130 (to Yamate); the Platform Project for Supporting Drug Discovery and Life Science Research (Basis for Supporting Innovative Drug Discovery and Life Science Research (BINDS)) from AMED under Grant Number JP20am0101123 (to Yamate); and the Grant for Advanced Research in Education (GARE), BANBEIS, MoE, Grant Number LS2018773 (to Karim).

Institutional Review Board Statement: The study was conducted according to the guidelines set by the Graduate School of Life and Environmental Sciences, Osaka Prefecture University. The protocol 
was approved by the ethical committee for the Care and Use of Experimental Animals of Osaka Prefecture University (Permit Nos. 23-24 and 25-85) and conformed to the Guidelines for the Conduct of Animal Experimentation of the Ministry of Health, Labor and Welfare Standards relating to the Care and Management of Experimental Animals and the Act on Welfare and Management of Animals, Japan. All efforts were made to minimize animal suffering. Specimens from humans were not used.

Informed Consent Statement: Not applicable.

Data Availability Statement: All data are contained within the article.

Acknowledgments: This work was supported partly by the JSPS KAKENHI Grant Numbers 26292152 and 19H03130 (to Yamate); the Platform Project for Supporting Drug Discovery and Life Science Research (Basis for Supporting Innovative Drug Discovery and Life Science Research (BINDS)) from AMED under Grant Number JP20am0101123 (to Yamate); and the Grant for Advanced Research in Education (GARE), BANBEIS, MoE, Grant Number LS2018773 (to Karim). We thank A. Bondoc and H. M. Golbar for their technical assistance.

Conflicts of Interest: The authors declare no conflict of interest.

\section{References}

1. Ricardo, S.D.; van Goor, H.; Eddy, A.A. Macrophage diversity in renal injury and repair. J. Clin. Investig. 2008, 118, 3522-3530. [CrossRef]

2. Henderson, N.C.; Mackinnon, A.C.; Farnworth, S.L.; Kipari, T.; Haslett, C.; Iredale, J.P.; Liu, F.T.; Hughes, J.; Sethi, T. Galectin-3 expression and secretion links macrophages to the promotion of renal fibrosis. Am. J. Pathol. 2008, 172, 288-298. [CrossRef]

3. LeBleu, V.S.; Taduri, G.; O'Connell, J.; Teng, Y.; Cooke, V.G.; Woda, C.; Sugimoto, H.; Kalluri, R. Origin and function of myofibroblasts in kidney fibrosis. Nat. Med. 2013, 19, 1047-1053. [CrossRef] [PubMed]

4. Fadok, V.A.; Bratton, D.L.; Konowal, A.; Freed, P.W.; Westcott, J.Y.; Henson, P.M. Macrophages that have ingested apoptotic cells in vitro inhibit proinflammatory cytokine production through autocrine/paracrine mechanisms involving TGF-beta, PGE2, and PAF. J. Clin. Investig. 1998, 101, 890-898. [CrossRef] [PubMed]

5. Border, W.A.; Noble, N.A. Evidence that TGF-beta should be a therapeutic target in diabetic nephropathy. Kidney Int. 1998, 54, 1390-1401. [CrossRef] [PubMed]

6. Li, J.; Qu, X.; Yao, J.; Caruana, G.; Ricardo, S.D.; Yamamoto, Y.; Yamamoto, H.; Bertram, J.F. Blockade of endothelial-mesenchymal transition by a Smad3 inhibitor delays the early development of streptozotocin-induced diabetic nephropathy. Diabetes 2010, 59, 2612-2624. [CrossRef] [PubMed]

7. Anders, H.J.; Ryu, M. Renal microenvironments and macrophage phenotypes determine progression or resolution of renal inflammation and fibrosis. Kidney Int. 2011, 80, 915-925. [CrossRef]

8. Lech, M.; Anders, H.J. Macrophages and fibrosis: How resident and infiltrating mononuclear phagocytes orchestrate all phases of tissue injury and repair. Biochim. Biophys. Acta 2013, 1832, 989-997. [CrossRef]

9. Mosser, D.M.; Edwards, J.P. Exploring the full spectrum of macrophage activation. Nat. Rev. Immunol. 2008, 8, 958-969. [CrossRef]

10. Sica, A.; Mantovani, A. Macrophage plasticity and polarization: In vivo veritas. J. Clin. Investig. 2012, 122, 787-795. [CrossRef]

11. Nahrendorf, M.; Swirski, F.K. Abandoning M1/M2 for a network model ofmacrophage function. Circ. Res. 2016, 119, 414-417. [CrossRef] [PubMed]

12. Damoiseaux, J.G.; Döpp, E.A.; Calame, W.; Chao, D.; MacPherson, G.G.; Dijkstra, C.D. Rat macrophage lysosomal membrane antigen recognized by monoclonal antibody ED1. Immunology 1994, 83, 140-147. [PubMed]

13. Sisino, G.; Bouckenooghe, T.; Aurientis, S.; Fontaine, P.; Storme, L.; Vambergue, A. Diabetes during pregnancy influences Hofbauer cells, a subtype of placental macrophages, to acquire a pro-inflammatory phenotype. Biochim. Biophys. Acta 2013, 1832, 1959-1968. [CrossRef] [PubMed]

14. Wijesundera, K.K.; Izawa, T.; Murakami, H.; Tennakoon, A.H.; Golbar, M.H.; Ichikawa, C.H.; Tanaka, M.; Kuwamura, M.; Yamate, J. M1- and M2-macrophage polarization in thioacetamide (TAA)-induced rat liver lesions; a possible analysis for hepato-pathology. Histol. Histopathol. 2014, 29, 497-511. [PubMed]

15. Polfliet, M.M.; Fabriek, B.O.; Daniëls, W.P.; Dijkstra, C.D.; van den Berg, T.K. The rat macrophage scavenger receptor CD163: Expression, regulation and role in inflammatory mediator production. Immunobiology 2006, 211, 419-425. [CrossRef]

16. Yamate, J.; Sato, K.; Ide, M.; Nakanishi, M.; Kuwamura, M.; Sakuma, S.; Nakatsuji, S. Participation of different macrophage populations and myofibroblasticcells in chronically developed renal interstitial fibrosis after cisplatin-induced canal injury in rats. Vet. Pathol. 2002, 39, 322-333. [CrossRef]

17. Yamate, J.; Machida, Y.; Ide, M.; Kuwamura, M.; Sawamoto, O.; LaMarre, J. Effects of lipopolysaccharide on the appearance of macrophage populations and fibrogenesis in cisplatin-induced rat renal injury. J. Exp. Toxicol. Pathol. 2004, 56, 13-24. [CrossRef]

18. Pervin, M.; Golbar, H.M.; Bondoc, A.; Izawa, T.; Kuwamura, M.; Yamate, J. Immunophenotypical characterization and influence on liver homeostasis of depleting and repopulating hepatic macrophages in rats injected with clodronate. Exp. Toxicol. Pathol. 2016, 68, 113-124. [CrossRef] 
19. Yamamoto, E.; Izawa, T.; Juniantito, V.; Kuwamura, M.; Sugiura, K.; Takeuchi, T.; Yamate, J. Involvement of endogenous prostaglandin E2 in tubular epithelial regeneration through inhibition of apoptosis and epithelial-mesenchymal transition in cisplatin-induced rat renal lesions. Histol. Histopathol. 2010, 25, 995-1007.

20. Yuasa, T.; Juniantito, V.; Ichikawa, C.; Yano, R.; Izawa, T.; Kuwamura, M.; Yamate, J. Thy-1 expression, a possible marker of early myofibroblast development, in renal tubulointerstitial fibrosis induced in rats by cisplatin. Exp. Toxicol. Pathol. 2013, 65, 651-659. [CrossRef]

21. Han, W.K.; Bailly, V.; Abichandani, R.; Thadhani, R.; Bonventre, J.V. Kidney Injury Molecule-1 (KIM-1): A novel biomarker for human renal proximal tubule injury. Kidney Int. 2002, 62, 237-244. [CrossRef] [PubMed]

22. van Timmeren, M.M.; van den Heuvel, M.C.; Bailly, V.; Bakker, S.J.; van Goor, H.; Stegeman, C.A. Tubular kidney injury molecule-1 (KIM-1) in human renal disease. J. Pathol. 2007, 212, 209-217. [CrossRef] [PubMed]

23. Mantovani, A.; Biswas, S.K.; Galdiero, M.R.; Sica, A.; Locati, M. Macrophage plasticity and polarization in tissue repair and remodelling. J. Pathol. 2013, 229, 176-185. [CrossRef] [PubMed]

24. Terada, N.; Karim, M.R.; Izawa, T.; Kuwamura, M.; Yamate, J. Expression of $\beta$-catenin in regenerating renal tubules of cisplatininduced kidney failure in rats. Clin. Exp. Nephrol. 2018, 22, 1240-1250. [CrossRef]

25. Liu, Y. Cellular and molecular mechanisms of renal fibrosis. Nat. Rev. Nephrol. 2011, 7, 684-696. [CrossRef]

26. Wang, Y.; Harris, D.C. Macrophages in renal disease. J. Am. Soc. Nephrol. 2011, 22, 21-27. [CrossRef]

27. Zhao, X.; Chen, X.; Zhang, Y.; George, J.; Cobbs, A.; Wang, G.; Li, L.; Emmett, N. Kidney injury molecule-1 is upregulated in renal lipotoxicity and mediates palmitate-induced tubular cell injury and inflammatory response. Int. J. Mol. Sci. 2019, 20, 3406. [CrossRef]

28. Rahman, N.; Pervin, M.; Kuramochi, M.; Karim, M.R.; Izawa, T.; Kuwamura, M.; Yamate, J. M1/M2-macrophage polarizationbased hepatotoxicity in d-galactosamine-induced acute liver injury in rats. Toxicol. Pathol. 2018, 46, 764-776. [CrossRef]

29. Kawamura, K.; Komohara, Y.; Takaishi, K.; Katabuchi, H.; Takeya, M. Detection of M2 macrophages and colony-stimulating factor 1 expression in serous and mucinous ovarian epithelial tumors. Pathol. Int. 2009, 59, 300-305. [CrossRef]

30. Liu, L.; Kou, P.; Zeng, Q.; Pei, G.; Li, Y.; Liang, H.; Xu, G.; Chen, S. CD4 ${ }^{+}$T Lymphocytes, especially Th2 cells, contribute to the progress of renal fibrosis. Am. J. Nephrol. 2012, 36, 386-396. [CrossRef]

31. Wynn, T.A. Cellular and molecular mechanisms of fibrosis. J. Pathol. 2008, 214, 199-210. [CrossRef] [PubMed]

32. Han, H.; Zhu, J.; Wang, Y.; Zhu, Z.; Chen, Y.; Lu, L.; Jin, W.; Yan, X.; Zhang, R. Renal recruitment of B lymphocytes exacerbates tubulointerstitial fibrosis by promoting monocyte mobilization and infiltration after unilateral ureteral obstruction. J. Pathol. 2017, 241, 80-90. [CrossRef] [PubMed] 